\title{
Qualidade Fisiológica de Sementes de Mamão Submetidas a Diferentes Métodos de Remoção da Sarcotesta
}

\section{Physiological Seed Quality of Papaya Submitted to Different Methods of Removal Sarcotesta}

Jerffeson Araujo Cavalcante ${ }^{1}$, Natali Almeida Evangelista Pereira ${ }^{2}$, Reginaldo Gomes Nobre ${ }^{3}$, Kilson Pinheiro Lopes ${ }^{4}$ Kelly Mara Marques $^{5}$

\begin{abstract}
RESUMO - As sementes de mamoeiro apresentam-se recobertas por membranas mucilaginosas denominadas de sarcotesta ou arilo e esclerotesta, que apresentam em sua constituição substâncias de potencial inibitório, responsáveis pelo controle da germinação. Objetiva-se com este trabalho determinar métodos favoráveis à remoção da sarcotesta em sementes de mamão, avaliando seus efeitos sobre a qualidade fisiológica das mesmas. O trabalho foi desenvolvido no Laboratório de Análise de Sementes e Mudas da Universidade Federal de Campina Grande, Campus Pombal, PB. As sementes foram extraídas manualmente de frutos sadios em completo estádio de maturação e lavadas em água corrente para a remoção do tecido placentário aderido às sementes. Em seguida, foram homogeneizadas e separadas em quatro grupos, os quais receberam os seguintes tratamentos: sementes intactas, sem remoção (testemunha); remoção com pressão sobre peneira; remoção pela fricção com areia autoclavada e remoção sob agitação com liquidificador. Após os tratamentos as sementes foram submetidas aos seguintes testes para avaliação de sua qualidade fisiológica: teste de germinação, primeira contagem de germinação, índice de velocidade de germinação, teste de emergência, índice de velocidade de emergência, condutividade elétrica e determinação da umidade. O tratamento de fricção das sementes em peneira foi o mais eficiente na remoção da sarcotesta garantindo os melhores valores de qualidade fisiológica das sementes. Os métodos de remoção, fricção com areia autoclavada e liquidificador mostraram-se pouco eficientes na remoção da sarcotesta de sementes de mamão.
\end{abstract}

Palavras-chave: Carica papaya L., mucilagem, viabilidade, vigor.

SUMMARY - The seeds of papaya are presented by mucilaginous membranes named sarcotesta or aryl and esclerotesta, they present in their composition substances with inhibitory potential, responsible for controlling the germination. The main objective of this paper is to determine favorable methods of removing sarcoseta in papaya seeds, evaluating their effcts over the physiologic quality of seeds. The work was developed in the Laboratory of Analysis of Seeds and Seedlings of the Federal University of Campina Grande, Campus Pombal, PB. The seeds were extracted manually from healthy full maturity stage and washed in running water to remove the placental tissue adhered to the seeds fruits. Then were homogenized and separated into four groups which received the following treatments: intact seeds without removal (witness); removal with pressure sieve, removing the friction with autoclaved sand removal and stirring with a blender. After treatment the seeds were subjected to the following tests to evaluate the physiological quality: germination, first count, speed index of germination, emergence test, emergence rate index, electrical conductivity and moisture. The friction treatment of the seeds in the sieve was the most efficient in removing sarcotesta ensuring the best values of seed quality. Removal methods, friction with autoclaved sand and blender proved inefficient in removing sarcotesta papaya.

Keywords: Carica papaya L., mucilage, viability, vigour.

1 Graduando em Agronomia - UFCG/CCTA - Universidade Federal de Campina Grande, Pombal-PB. E-mail: jerffeson000@hotmail.com

2 Graduando em Agronomia - UFCG/CCTA - Universidade Federal de Campina Grande, Pombal-PB. E-mail: natalipb@hotmail.com

3 Eng. Agr. D. Sc., Professor Adjunto da Unidade Acadêmica de Ciências Agrárias - UFCG/CCTA - Universidade Federal de Campina Grande, Pombal-PB. E-mail: rgomesnobre@ccta.ufcg.edu.br

4 Eng. Agr. D. Sc., Professor Adjunto da Unidade Acadêmica de Ciências Agrárias - UFCG/CCTA - Universidade Federal de Campina Grande, Pombal-PB. E-mail: rgomesnobre@ccta.ufcg.edu.br

5 Graduando em Agronomia - UFCG/CCTA - Universidade Federal de Campina Grande, Pombal-PB. E-mail: kellymaara@hotmail.com 


\section{INTRODUÇÃO}

O Brasil vem destacando-se como um dos maiores produtores de mamão do mundo (Carica papaya L.), com aproximadamente 31.000 ha de área cultivada e com produção de 1,6 milhões de toneladas, em 2012 (IBGE, 2012). Segundo a FAO (2013), a produção mundial de mamão representa $10 \%$ da produção mundial de frutas tropicais, girando em torno de 11 milhões de toneladas, das quais $37 \%$ são produzidas na América Latina e Caribe. Os principais produtores mundiais são a Índia, Brasil, Indonésia, República Dominicana, Nigéria e México.

A propagação do mamão é realizada preferencialmente por meio de sementes, por tratar-se de um método rápido, econômico e prático. No entanto, sua germinação é considerada lenta, desuniforme e irregular, o que prejudica a formação de mudas (TOKUHISA et al., 2007).

A estimativa da utilização de sementes de mamão, no Brasil, é de aproximadamente $5.000 \mathrm{~kg}$ por ano, o que significa uma quantia superior a US\$ 4 milhões. Em função do custo elevado, vários produtores optam por produzir suas próprias sementes, reproduzindo em suas lavouras materiais de baixo padrão de qualidade genética, permanecendo no campo cultivares sem expressão econômica, com risco de disseminação de doenças de grande severidade para a cultura (ALVES et al., 2003).

Existem vários fatores que podem afetar a produção. Dentre eles pode-se citar: tipo de solo, correção e adubação do solo, fornecimento de água e práticas culturais (MARIN et al., 1987). Segundo Medina (1989), outro fator de grande importância, porém em nível de plantio, seria a porcentagem de germinação das sementes que, por vez, no caso do mamão pode ser afetada pela presença ou não de sarcotesta.

A sarcotesta é um material gelatinoso provido de compostos fenólicos que protege a semente, podendo vir a comprometer a germinação, tornando-a lenta e desuniforme, bem como acarretar desenvolvimento heterogêneo das plântulas no viveiro (MARIN et al., 1987). Segundo Carvalho; Nakagawa (2000), estes compostos podem restringir a entrada de oxigênio no interior da semente, impedindo, portanto, a germinação.

Existem diversas técnicas de remoção de polpa e mucilagem de sementes, para as diferentes espécies. Entretanto, é necessária a realização de pesquisas visando o estabelecimento de métodos mais eficientes e econômicos, que garantam uma boa percentagem de germinação e que assegurem um bom potencial de armazenamento. (PEREIRA; DIAS, 2000).

De acordo com Carvalho; Nakagawa (2000), a remoção da sarcotesta pode ser efetuada através da fermentação, secagem, remoção mecânica, ácidos, bases, sais e enzimas, eventualmente, esses são os métodos mais empregados.

Diante do exposto, objetiva-se com este trabalho determinar o melhor método de remoção da sarcotesta em sementes de mamão, avaliando seus efeitos sobre a qualidade fisiológica das mesmas.

\section{MATERIAL E MÉTODOS}

O trabalho foi realizado no Laboratório de Análise de Sementes e Mudas do Centro de Ciências e Tecnologia Agroalimentar da Universidade Federal de Campina Grande, Campus Pombal, PB. Foram utilizados frutos de mamoeiro sadios e fisiologicamente maduros, do grupo Formosa obtidos em feira livre na cidade de Pombal - PB.

As sementes foram extraídas dos frutos com auxílio de uma colher e lavadas em água corrente para a remoção da placenta e em seguida homogeneizadas e separadas em quatro grupos, os quais receberam os seguintes tratamentos quanto à maneira de remoção da sarcotesta:

- Remoção com pressão sobre peneira: as sementes foram colocadas em uma peneira com malha de aço inferior ao tamanho da semente, sendo pressionadas contra esta com o auxílio das mãos até o rompimento da sarcotesta. Durante esta operação, a peneira esteve sob uma torneira com jato de água corrente, para facilitar a separação;

- Remoção pela fricção com areia autoclavada: as sementes foram colocadas em um recipiente, misturadas com uma quantidade de areia equivalente ao dobro do seu volume e friccionadas com o auxílio das mãos. Em seguida, todo o conteúdo do recipiente foi colocado em uma peneira com malha inferior ao tamanho da semente, para promover a sua separação da areia, sob uma torneira com jato de água corrente;

- Remoção com liquidificador: as sementes foram misturadas com uma quantidade de água equivalente a três vezes o seu volume e colocadas no liquidificador. Inicialmente as hélices do aparelho foram protegidas com fita crep, a fim de diminuir o impacto direto da semente com a lâmina cortante, (de uma forma intermitente, ou seja, ao adquirir velocidade o aparelho era desligado).

- Testemunha: sementes intactas não submetidas a qualquer tratamento de remação da sarcotesta.

Após os tratamentos as sementes foram submetidas aos seguintes testes para avaliação de sua qualidade fisiológica:

- Determinação do grau de umidade: realizada pelo método da estufa, a $105^{\circ} \mathrm{C}$ durante 24 horas, de acordo com as Regras para Análise de Sementes (BRASIL, 2009), com resultados expressos em porcentagem (base úmida).

- Teste de germinação: foi conduzido segundo recomendações das Regras para Análise de Sementes (BRASIL, 2009), em substrato papel tipo Germitest, na forma de rolo, umedecido com água destilada na proporção de 2,5 vezes o peso do papel seco. Os rolos foram mantidos em germinador regulado à temperatura alternada de $20-30{ }^{\circ} \mathrm{C}$, com fotoperíodo de 8 horas. A avaliação da porcentagem de germinação foi realizada a partir de contagens diárias do $7^{\circ}$ ao $14^{\circ}$ dia após a 
semeadura, sendo os resultados expressos em porcentagem.

- Primeira contagem de germinação: no sétimo dia após a montagem do teste de germinação, foi realizada a primeira contagem de germinação, com os resultados expressos em porcentagem (BRASIL, 2009).

- Índice de velocidade de germinação: juntamente com o teste de germinação, efetuaram-se contagens diárias de plântulas normais, do $7^{\circ}$ ao $14^{\circ}$ dia, empregando-se a fórmula proposta por Maguire (1962).

$$
I V G=\frac{G 1}{N 1}+\frac{G 2}{N 1}+\ldots \frac{G n}{N n}
$$

Onde:

$\mathrm{G}_{1}, \mathrm{G}_{2}, \mathrm{G}_{\mathrm{n}}=$ número de plântulas germinadas.

$\mathrm{N}_{1}, \mathrm{~N}_{2}, \mathrm{~N}_{\mathrm{n}}=$ número de dias desde a primeira, segunda, até a última contagem.

- Emergência de plântulas: foi realizada com quatro repetições de 25 sementes por tratamento, distribuídas em bandejas de poliestireno expandido contendo substrato comercial Hortmix ${ }^{\circledR}$. As bandejas foram mantidas em ambiente protegido, sendo realizadas irrigações diárias com o intuito de manter a umidade do substrato. As avaliações foram feitas diariamente, do primeiro dia após a montagem do teste até o trigésimo dia, com a contagem de plântulas que emergiram assim consideradas, quando o cotilédone romper o substrato, com o resultado expresso em porcentagem.

- Índice de velocidade de emergência (IVE): realizado juntamente com o teste de emergência de plântulas, por meio de contagens diárias do número de plântulas com cotilédone visível acima do substrato e o resultado obtido segundo fórmula proposta por Maguire (1962).

- Condutividade elétrica (CE): conduzido pelo método massal, utilizando-se quatro repetições de 20 sementes. As repetições foram pesadas em balanças com precisão de $0,001 \mathrm{~g}$, colocadas em copos plásticos contendo $25 \mathrm{~mL}$ de água deionizada e mantidas em câmara de germinação, regulada a $25^{\circ} \mathrm{C}$, durante duas horas, conforme Oliveira et al., (2005) e Vidigal et al., (2008). As leituras da condutividade elétrica foram realizadas com auxílio de um condutivímetro (Tenopon mCA-150) e os valores médios, para cada lote, expressos em $\mu \mathrm{S} \mathrm{cm}^{-1} \mathrm{~g}^{-1}$ de semente.

Empregou-se o delineamento inteiramente casualizado, com quatro repetições por tratamento. Os dados obtidos foram submetidos à análise de variância com médias dos parâmetros qualitativos comparados pelo teste de Tukey a $5 \%$ de probabilidade, utilizando-se o programa estatístico SISVAR.

\section{RESULTADOS E DISCUSSÃO}

Os dados do teor de umidade, porcentagem de germinação, primeira contagem e índice de velocidade de germinação estão apresentados na Tabela 1. As sementes submetidas à remoção da sarcotesta por meio da pressão sobre peneira apresentaram maior porcentagem de germinação, seguida das sementes tratadas com remoção com liquidificador e areia autoclavada que não diferiram estatisticamente entre si.

O menor desempenho apresentado pelas sementes submetidas à remoção da sarcotesta com o uso do liquidificador na germinação, provavelmente, ocorreu devido a danos físicos provocado pelo atrito proporcionado pelas hélices do liquidificador, que levaram à inviabilização do embrião, o que pode ser endossado com o elevado percentual de sementes não germinadas. $\mathrm{O}$ mesmo pode ter ocorrido com as sementes submetidas à remoção da sarcotesta com areia autoclavada, possivelmente, o atrito provocado pelas partículas de areia podem ter comprometido a integridade física do embrião.

As sementes não submetidas à remoção da sarcotesta (testemunha) apresentaram baixa porcentagem de germinação (Tabela 1 ). Ainda na Tabela 1 , verifica-se que as sementes com sarcotesta não apresentaram emissão de estruturas visíveis no primeiro dia de contagem de germinação. Araujo et al. (2005), verificaram em sua pesquisa de armazenamento e qualidade fisiológica de sementes de mamão, que a semente do mamoeiro apresenta-se envolvida por duas membranas (sarcotesta e esclerotesta), nas quais existe predominância de substâncias inibidoras e estas são citadas, como prováveis, responsáveis pelo controle da germinação das sementes.

As sementes não submetidas à remoção da sarcotesta (testemunha) também apresentaram uma redução na velocidade de germinação, conforme observase na Tabela 1, quando comparadas àquelas submetidas a remoção da sarcotesta com pressão sobre peneira, que apresentaram valores significativamente superiores de velocidade na germinação, seguida daquelas submetidas à fricção em areia autoclavada e liquidificador, que não diferiram entre si.

Freitas et al. (2011) avaliando diferentes métodos de remoção da sarcotesta na germinação de sementes de jaracatiá (Jaracatia spinosa Aubl.), verificaram que o índice de velocidade de germinação foi significativamente influenciado, de forma negativa, pele presença da sarcotesta.

Melo; Seleguini (2013) trabalhando com diferentes métodos físicos de remoção da sarcotesta em sementes de mamão, constataram que a presença da sarcotesta nas sementes influenciou de forma negativa a emergência e o crescimento radicular de plântulas de mamão. Esses autores ainda relatam que a pressão em peneira com água corrente, a fricção com areia grossa e o esfregaço com escova de cerdas plásticas, são métodos adequados para remoção da sarcotesta de sementes de mamão. 
Tabela 1 - Valores médios de umidade (U), germinação (GER), primeira contagem de germinação (PCG) e índice de velocidade de germinação (IVG) de sementes de mamoeiro submetidas a diferentes tratamentos de remoção da sarcotesta. CCTA/UFCG, Pombal - PB, 2013.

\begin{tabular}{ccccc}
\hline Tratamentos & $\mathrm{U}(\%)$ & GER $(\%)$ & PCG $(\%)$ & IVG \\
\hline Testemunha & $40,69^{*} \mathrm{a}$ & $19,00 \mathrm{c}$ & - & $0,27 \mathrm{c}$ \\
Remoção com areia & $10,32 \mathrm{~b}$ & $45,00 \mathrm{~b}$ & $10,00 \mathrm{a}$ & $1,24 \mathrm{~b}$ \\
Remoção com peneira & $10,57 \mathrm{~b}$ & $70,00 \mathrm{a}$ & $9,00 \mathrm{a}$ & $1,91 \mathrm{a}$ \\
Remoção com liquidificador & $10,39 \mathrm{~b}$ & $54,00 \mathrm{~b}$ & $8,00 \mathrm{a}$ & $1,36 \mathrm{~b}$ \\
\hline $\mathrm{CV}$ & 4,63 & 13,81 & 9,60 & 16,80 \\
\hline
\end{tabular}

*Médias seguidas pela mesma letra na coluna não difere entre sí pelo teste Tukey a 5 \% de probabilidade.

Na Tabela 2, verifica-se que as sementes não submetidas à remoção da sarcotesta (testemunha) e as submetidas à fricção sobre peneira apresentaram menores valores de condutividade elétrica, evidenciando possivelmente menores danos físicos às sementes, ao contrário do observado nos demais métodos de remoção. Já que o teste de condutividade elétrica baseia-se no princípio de que, com o processo de deterioração, ocorre a lixiviação de constituintes celulares das sementes embebidas em água, devido à perda da integridade dos sistemas de membranas celulares. Assim, baixa condutividade indica sementes com alto vigor e alta condutividade, ou seja, maior quantidade de lixiviados determina baixo vigor (VIEIRA, 1994; VIEIRA; KRZYZANOWSKI, 1999; PANOBIANCO; MARCOS FILHO, 2001).

A remoção da sarcotesta com liquidificador apresentou alta quantidade de sementes danificadas, mesmo as hélices estando revestidas com fita adesiva. Os danos foram provocados, provavelmente, pelo choque das sementes contra a hélice e, ou, a parede do copo do liquidificador. Pode-se afirmar isso por meio do teste de condutividade elétrica (Tabela 2), onde as sementes liberaram grande quantidade de lixiviados para a solução.
Costa et al. (2008); Ferreira et al. (2008) verificaram, em teste de condutividade elétrica, que a extração com liquidificador provocou aumento de lixiviados no meio, possivelmente por ter comprometido a integridade do tegumento das sementes.

A remoção da sarcotesta com pressão sobre peneira garantiu os maiores valores de emergência de plântulas (Tabela 2), embora não tenha diferido das sementes com sarcotesta (testemunha). Osipi et al. (2011) avaliando a influência de métodos de remoção do arilo na qualidade fisiológica de sementes de maracujá afirmam que nos métodos de remoção do arilo, as condições de viveiro proporcionaram percentuais de emergência em plântulas, que superaram os resultados obtidos em condições de laboratório.

Quando as sementes foram avaliadas com a sarcotesta (testemunha), observa-se que as mesmas apresentaram boa porcentagem de emergência de plântulas, mas baixa velocidade de emergência quando comparadas àquelas em que se empregou algum método de remoção da sarcotesta (Tabela 2). Schmildt et al. (1993) constataram que a velocidade de emergência de plântulas de mamoeiro foi menor sem a extração da sarcotesta.

Tabela 2 - Valores médios de condutividade elétrica (CE), emergência plântulas (EMER) e índice de velocidade de emergência de plântulas (IVE) oriundas de sementes de mamoeiro submetidas a diferentes tratamentos de remoção da sarcotesta, CCTA/UFCG, Pombal - PB, 2013.

\begin{tabular}{|c|c|c|c|}
\hline Tratamentos & $\mathrm{CE}(\mu \mathrm{S} / \mathrm{cm} / \mathrm{g})$ & $\operatorname{EMER}(\%)$ & IVE \\
\hline Testemunha & $115,41 \mathrm{~b}$ & $76,00 \mathrm{a}$ & $5,29 \mathrm{~b}$ \\
\hline Remoção com areia & $329,82 \mathrm{a}$ & $66,00 \mathrm{~b}$ & $5,89 a$ \\
\hline Remoção com peneira & $136,97 \mathrm{~b}$ & 77,00 a & $5,72 \mathrm{a}$ \\
\hline Remoção com liquidificador & $411,47 \mathrm{a}$ & $64,00 \mathrm{~b}$ & $5,84 \mathrm{a}$ \\
\hline $\mathrm{Cv}$ & 24,14 & 9,69 & 2,65 \\
\hline
\end{tabular}

*Médias seguidas pela mesma letra na coluna não difere entre si pelo teste Tukey a $5 \%$ de probabilidade.

Portanto, os métodos físicos utilizados na remoção da sarcotesta não apresentaram eficiência na germinação e emergência das sementes, exceto as sementes submetida a pressão sobre peneira, onde observou-se os melhores valores de viabilidade e vigor, sendo este um método prático, econômico e eficiente, capaz de remover a sarcotesta em sementes de mamoeiro sem comprometer a qualidade fisiológica.

\section{CONCLUSÃO}


A presença de sarcotesta afetou negativamente a germinação e o índice de velocidade de germinação e emergência de sementes de mamão;

A remoção da sarcotesta das sementes de mamoeiro por meio da pressão em peneira, mostrou-se eficiente melhorando a velocidade e o total de germinação.

\section{REFERÊNCIAS}

ALVES, F.L.; PACOVA, B.E.V.; GALVAES, P.A.O Seleção de plantas matrizes de mamão, grupo Solo, para produção de sementes. In: MARTINES, D.S.; COSTA, A.F.S. (Ed.). A cultura do mamoeiro: tecnologias de produção. Vitória: Incaper, p.103-114, 2003.

ARAÚJO, E.C.; BALBINOT, E.; MENDONÇA, A.V.R.; SILVA, R.F. Efeito do armazenamento na qualidade fisiológica de sementes de mamão (Carica papaya $L$.) em função da posição no fruto. Papaya Brasil. 2005. Disponível em: http://www.fundagres.org.br/downloads/pimamao/2005_e mentes_mudas_08.pdf. Acesso: 19 jun. 2014.

BRASIL. Ministério da Agricultura, Pecuária e Abastecimento. Regras para análise de sementes. Brasília: Mapa/ACS, p. 399, 2009.

CARVALHO, N.M.; NAKAGAWA, J. Sementes: ciência, tecnologia e produção. 4ed. Jaboticabal: Funep, p. 588,2000

COSTA, P. N.; FERREIRA, G.; BARON, D. Efeito de métodos de extração de arilo na qualidade fisiológica de sementes de Passiflora edulis f. flavicarpa. In: CONGRESSO BRASILEIRO DE FRUTICULTURA, 20., 2008, Vitória. Anais... Vitória: Sociedade Brasileira de Fruticultura, p.625-630, 2008.

FAO. Produção Mundial de mamão de 2013. Disponível em: www.cnpmf.embrapa.br/. Atualizado em 16/12/2013. Acesso em 10/04/2014.

FERREIRA, G.; COSTA, P. N.; BARON, D.; CORSATO, J. M. Avaliação da qualidade fisiológica de sementes de Passiflora cincinnata Mast. submetidas a diferentes métodos de extração. In: CONGRESSO BRASILEIRO DE FRUTICULTURA, 20., 2008, Vitória. Anais... Vitória: Sociedade Brasileira de Fruticultura, p. 625-630, 2008.

FREITAS, S.J.; BARROSO, D. G.; SILVA, R. ; F MARTINS, V. H. C. R.; FREITAS, M. D. S.; FERREIRA, P. R. Métodos de remoção da sarcotesta na germinação de sementes de jaracatiá. Revista Árvore, Viçosa-MG, v.35, n.1, p.91-96, 2011.

INSTITUTO BRASILEIRO DE GEOGRAFIA E ESTATÍSTICA. Produção Agrícola Municipal: culturas temporárias e permanentes (2011). Rio de Janeiro, 2012. $97 \mathrm{p}$.

MAGUIRE, J.D. 1962. Speed of germination aid in selection and evaluation for seedling vigour. Crop Science, v.2, p.176-177, 1962.

MARIN, J. L. D.; GOMES, J. A.; SALGADO, J. S. Recomendação para a cultura do mamoeiro cv. Solo do Estado do Espírito Santo. 3.ed., Vitória: p. 64, 1987.

MEDINA, J.C. Cultura. In: INSTITUTO DE TECNOLOGIA DE ALIMENTOS. Mamão. 2. ed., Campinas: Instituto Campineiro de Ensino Agrícola, p.1177, 1989.

MELO, A. P. C.; SELEGUINI, A. Estádio de maturação de frutos e remoção física da sarcotesta na produção de mudas de mamão. Comunicata Scientiae v. 4 , n.1, p. 20$25,2013$.

OLIVEIRA, S. R .S.; NOVEMBRE, A. D. L. C. Teste de condutividade elétrica para sementes de pimentão. Revista Brasileira de Sementes, Brasília. v. 27, n.1, p.31-36, 2005.

OSIPI, E. A. F.; LIMA, C. B.; COSSA C. A. Influência de métodos de remoção do arilo na qualidade fisiológica de sementes de Passiflora alata Curtis. Revista Brasileira de Fruticultura, Jaboticabal - SP, Volume Especial, p. 680-685, 2011

PANOBIANCO, M.; VIEIRA, R. D.; PERECIN, D. Electrical conductivity as na indicator of pea seed aging of stored at different temperatures. Scientia Agricola, v.64, n.2, p.119-124, 2007.

PEREIRA, K. J. C.; DIAS, D. C. F. S.; Germinação e vigor de sementes de maracujá-amarelo (Passiflora edulis sims. f. flavicarpa deg.) submetidas a diferentes métodos de remoção da mucilagem. Revista Brasileira de Sementes, v. 22, n. 1, p. 288-291, 2000.

PANOBIANCO, M.; VIEIRA R. D.; PERECIN D. Electrical conductivity as na indicator of pea seed aging of stored at different temperatures. Scientia Agricola, v. 64, n. 2, p.119-124, 2007.

SCHMILDT, E. R., FRONZA, V., DIAZ, J. L. S., UNÊDA, S. H., ALVARENGA, E. M. 1993. Comparação de métodos físicos de remoção da sarcotesta e de métodos de secagem de mamoeiro (Carica papaya L.). Revista Brasileira de Sementes v. 15, p. 147-151,

TOKUHISA, D., D.C.F.S. DIAS, E.M. ALVARENGA, P.C. HILST AND A.J. DEMUNER.. Compostos fenólicos inibidores da germinação em sementes de mamão (Carica papaya L.). (Em Português, com resumo em inglês). 
Revista Brasileira de Sementes, Brasília, v.29, n.3, p.80188, 2007.

VIDIGAL, D.S.; LIMA, J.S.; BHERING, M.C.; DIAS, D.C.F.S. Teste de condutividade elétrica para semente de pimenta. Revista Brasileira de Sementes. Brasília, v.30, n.1, p.168-174, 2008.

VIEIRA, R. D.; CARVALHO, N. M.; SADER, R. Testes de vigor e suas possibilidades de uso. In: VIEIRA, R.D.; CARVALHO, N.M. (ed.), Testes de vigor em sementes. Jaboticabal: FUNEP, p.31 - 47. 1994.

VIEIRA, R. D.; KRZYZANOWSKI, F. C. Teste de condutividade elétrica. In: KRZYZANOWSKI, F. C.; VIEIRA, R. D.; FRANÇA NETO, J. B. (ed.) Vigor de sementes: conceitos e testes. Londrina: ABRATES, cap.4, p.1-26. 1999. 